\title{
Componentes de rendimento e produtividade do feijoeiro comum submetido à inoculação e co- inoculação com estirpes de Rhizobium tropici e Azospirillum brasilense
}

Yield components and grain yield of common-bean submitted to the inoculation and co-inoculation of Rhizobium tropici and Azospirillum brasilense strains

\author{
João Henrique Schossler ${ }^{1}$, Leandro Meert ${ }^{2 *}$, Diego Ary Rizzardi ${ }^{3}$, Leandro Michalovicz ${ }^{4}$ \\ ${ }^{1}$ Engenheiro agrônomo, e-mail: joaohenrique_93@hotmail.com \\ 2 Professor, Departamento de Agronomia, Faculdade Integrado de Campo Mourão, e-mail: \\ leandro.meert@grupointegrado.br (Autor para correspondência) \\ ${ }_{3}^{3}$ Doutorando em genética e melhoramento de plantas, UEM, e-mail: rizzardiary@gmail.com \\ ${ }_{4}^{4}$ Doutor em Agronomia, e-mail: leandromichalovicz@gmail.com
}

Artigo enviado em 24/06/2016, aceito em 23/09/2016 e publicado em 13/10/2016.

Resumo - O feijão é um dos alimentos mais comuns do povo brasileiro sendo cultivado em várias regiões do País. Assim, o estudo teve como objetivo avaliar a influência da inoculação e co-inoculação com bactérias do gênero Rhizobium e Azospirillum sobre os componentes de produção e produtividade de grãos do feijoeiro comum. $\mathrm{O}$ experimento foi realizado no ano agrícola 2015/2016 com quatro tratamentos (T1 = Testemunha (sem inoculação); T2= Inoculação com Rhizobium tropici; T3= Inoculação com Azospirillum brasilense e T4= Co-inoculação com Rhizobium tropici + Azospirillum brasilense). O delineamento utilizado foi de blocos completos com tratamentos ao acaso, com cinco repetições. Foram avaliadas a altura de plantas $(\mathrm{cm})$, diâmetro do colmo $(\mathrm{cm})$, número de vagens por planta, número de grãos por vagem, massa de mil grãos $(\mathrm{g})$ e produtividade de grãos $\left(\mathrm{kg} \cdot \mathrm{ha}^{-1}\right)$. Os resultados mostraram em todos os tratamentos que receberam inoculação, independente do microrganismo utilizado, tiveram plantas maiores e maior número de vagens por planta em relação à testemunha. A co-inoculação com Rhizobium tropici + Ažospirillum brasilense apresentou maior massa de mil grãos $(253,36 \mathrm{~g})$ e a maior produtividade $\left(2448,45 \mathrm{~kg} \mathrm{ha}^{-1}\right)$.

Palavras-chave - Phaseolus vulgaris L., fixação biológica, simbiose.

Abstract - Common-bean is one of the most common food to Brazilian people being cultivated in several regions of the country. Thereby, the aim of this work was to evaluate the influence of inoculation and co-inoculation with bacteria of the genus Rhizobium and Arospirillum on yield components and grain yield of common bean. The experiment was set up in the 2015/2016 harvest season. With four treatments: T1= Control (without inoculation); T2= Inoculation with Rhizobium tropici; T3= Inoculation with Azospirillum brasilense e T4= co-inoculation with Rhizobium tropici + Azospirillum brasilense. Thus, the experiment consisted in a randomized complete block design with five replications. There were evaluated plant height $(\mathrm{cm})$, stem diameter $(\mathrm{cm})$, number of pods per plant, number of grains per pod, mass of 100 grains $(\mathrm{g})$ and yield $\left(\mathrm{kg} \mathrm{ha}^{-1}\right)$. The results showed that all treatments that received inoculation, independent of the utilized microorganism, had increased plant high and the number of pods per plant in relation to the control. The co-inoculation with Rhizobium tropici + Azospirillum brasilense showed both the highest mass of 1000 grains (253,36 g) and yield $\left(2448,45 \mathrm{~kg} \mathrm{ha}^{-1}\right)$.

Keywords - Phaseolus vulgaris, biological fixation, symbiosis.

\section{INTRODUÇÃO}

O feijoeiro comum (Phaseolus vulgaris L.) possui papel de destaque no cenário nacional por ser uma importante fonte de proteína na alimentação e, social por envolver um grande número de pessoas na sua produção, principalmente pequenos produtores. No ano agrícola de 2014/2015 a produção no País foi de 3,1 mil toneladas em 3 mil hectares cultivados com produtividade de 1,03 t. ha ${ }^{-1}$, onde o estado do Paraná é o principal produtor respondendo por $22,5 \%$ da produção nacional (CONAB, 2015).

A baixa produtividade no Brasil está relacionada, principalmente, à baixa tecnologia de produção, onde o fornecimento de nutrientes merece destaque. Nesse contexto, um dos insumos agrícolas mais importantes para o feijoeiro atingir elevada produtividade é o fertilizante nitrogenado. Assim, alternativas que minimizem a aplicação de adubos nitrogenados nas áreas de produção agrícola estão sendo objetos de inúmeras pesquisas. Neste contexto, a FBN assume grande importância, pois, as exigências de 
nitrogênio no feijoeiro podem ser supridas pela mesma (RUFINI et al., 2011), além dos baixos custos para o produtor, representaando uma alternativa viável na sustentabilidade agrícola e da redução da lixiviação do nitrato reduzindo de maneira drástica os impactos ambientais propiciados pelo uso de fontes nitrogenadas artificiais (PELEGRIN et al., 2009).

Atualmente, o inoculante comercial para o feijoeiro no Brasil é produzido com uma espécie de rizóbio adaptado à solos tropicais, o Rhizobium tropici, que consegue fixar entre 20 e $30 \%$ do nitrogênio que a planta necessita por meio de fixação biológica, podendo contribuir com até a $40 \mathrm{~kg} \mathrm{ha}{ }^{-1}$ de nitrogênio (FANCELLI; DOURADO NETO, 2007).

Além dos rizóbios específicos para o grupo das leguminosas, existem outros microrganismos que podem maximizar esse tipo de benefício e que fazem parte do grupo das bactérias promotoras do crescimento de plantas (BPCP). Um dos grupos promissores é representado por bactérias associativas capazes de promover o crescimento das plantas por meio de vários processos, como a produção de hormônios de crescimento e a capacidade de realizar fixação biológica do nitrogênio, destacando-se as pertencentes ao gênero Azospirillum (HUNGRIA et al., 2015).

Neste cenário, a co-inoculação, com bactérias simbióticas e assimbióticas, tem sido estudada em leguminosas como alternativa para aumentar a produtividade de grãos. No feijoeiro, essa técnica consiste na utilização de combinações de diferentes bactérias produzindo efeito sinérgico, em que se superam os resultados produtivos obtidos quando utilizadas na forma isolada (HUNGRIA et al., 2013).

Em leguminosas, os primeiros trabalhos de coinoculação com bactérias simbióticas e associativas foram realizados na cultura da soja (BENINTENDE et al., 2010), contudo a técnica também pode melhorar o desempenho do feijoeiro aumentando o aporte de nitrogênio para a mesma, diminuindo assim a dependência de adubos nitrogenados, atendendo assim a um dos principais requisitos da agricultura moderna, a sustentabilidade ambiental (CHAPARRO et al., 2012).

O efeito benéfico da associação do Ažospirillum com bactérias do gênero Rbizobium em leguminosas se deve principalmente a capacidade da bactéria em produzir fitormônios como auxinas e citocininas, que resulta em um maior desenvolvimento do sistema radicular, e, consequentemente na exploração de um volume maior de solo (DE BRUIJN, 2015), a nodulação precoce, pois o Azospirillum coloniza as raízes antes do Rhizobium e produz sinais flavonóides que atraem o Rhizobium (CHIBEBA et al., 2008), além do aumento no número de nódulos (COSTA et al., 2014).
Nesse contexto, o objetivo do estudo foi verificar a influência da inoculação e co-inoculação em sementes com estirpes de Rhizobium tropici e Azospirillum brasiliense sobre os componentes de rendimentos e produtividade de grãos do feijoeiro comum.

\section{MATERIAL E MÉTODOS}

O estudo foi realizado no município de Campina da Lagoa - PR (24 $35^{\prime} 21^{\prime \prime}$ S e $\left.52^{\circ} 49^{\prime} 34^{\prime \prime} \mathrm{O}\right)$ e altitude de 555 metros. O clima da região é classificado como subtropical úmido mesotérmico, com verões quentes e geadas pouco frequentes e com tendência de concentração das chuvas nos meses de verão, sem estação seca definida, de acordo com a classificação de Köppen. O solo é classificado como Latossolo Vermelho distroférrico (EMBRAPA, 2013), com as seguintes características químicas na camada de $0-20 \mathrm{~cm}$ : $\mathrm{pH} \mathrm{CaCl}_{2}=5,6 ; \mathrm{H}+\mathrm{Al}(\mathrm{SMP})=3,94 \mathrm{cmol}_{\mathrm{c}} \mathrm{dm}^{-3} ;$ Matéria orgânica $=2,30 \% ; \mathrm{P}($ Mehlich 1$)=7,0 \mathrm{mg} \mathrm{dm}^{-3} ; \mathrm{Ca}=$ $6,00 \mathrm{cmol}_{\mathrm{c}} \mathrm{dm}^{-3} ; \mathrm{Mg}=1,70 \mathrm{cmol}_{\mathrm{c}} \mathrm{dm}^{-3} ; \mathrm{K}=0,30 \mathrm{cmol}_{\mathrm{c}}$ $\mathrm{dm}^{-3}$ e $\mathrm{V} \%=67 \%$. A área se encontra sob sistema de plantio com semeadura direta a mais de 15 anos, com alternância de cultura em sucessão no verão com milho, soja ou feijão e no inverno com trigo ou aveia.

Os quatro tratamentos avaliados foram: (T1= Sem inoculação; T2= Inoculação com Rhizobium tropici; T3= Inoculação com Azospirillum brasilense, T4= Coinoculação com Rhizobium tropici + Azospirillum brasilense) e delineados em experimento de blocos completos com tratamentos ao acaso, com cinco repetições. O modelo matemático e estatístico adotado foi: $\mathrm{Y}_{\mathrm{ij}}=\mathrm{m}+\mathrm{t}_{\mathrm{i}}+\mathrm{b}_{\mathrm{j}}+$ $\mathrm{e}_{\mathrm{ij}}$, em que; $\mathrm{Y}_{\mathrm{ij}}$ é o: valor a ser observado referente ao tratamento "i" no bloco "j"; $m$ é a média geral do experimento; $t_{i}$ com $\mathrm{i}=1,2, \ldots \mathrm{I}$, é o efeito de tratamento; $b_{j} \operatorname{com} j=1,2, \ldots J$, é o efeito de blocos e e é o erro experimental, admitindo-se $\mathrm{e}_{\mathrm{ij}} \sim \mathrm{NID}\left(0, \sigma_{\text {comum }}^{2}\right.$ ), cada parcela

12

$\mathrm{m}^{2}$ $3 \times 4)$.

A semeadura foi realizada manualmente no dia 12 de setembro de 2015 com o auxílio de matracas. A cultivar IPR Tangará ${ }^{\circledR}$ é classificada dentro do grupo carioca, apresentando hábito de crescimento indeterminado e ciclo médio de 87 dias. O espaçamento utilizado foi $0,5 \mathrm{~m}$ entre fileiras com 14 sementes por metro, totalizando um estande final 280000 plantas ha ${ }^{-1}$. A adubação foi realizada com base nas recomendações para a cultura, sendo à lanço e com 20,60 e $90 \mathrm{~kg} \mathrm{ha}^{-1}$, de nitrogênio, $\quad \mathrm{P}_{2} \mathrm{O}_{5}$ e $\quad \mathrm{K}_{2} \mathrm{O}$ respectivamente. 
$\mathrm{Na}$ inoculação com Rhizobium tropici utilizou-se o produto comercial Masterfix feijão ${ }^{\circledR}$ na dosagem de $100 \mathrm{~g}$ por saca de $50 \mathrm{~kg}$ de semente. Para o Azospirillum brasilense foi utilizado o produto Masterfix gramíneas ${ }^{\circledR}$ na dosagem de $100 \mathrm{ml} \mathrm{ha}{ }^{-1}$ e a co-inoculação foi obtida com a mistura dos dois produtos nas respectivas doses recomendadas. As aplicações de fungicidas e inseticidas durante o ciclo da cultura foram realizadas conforme as recomendações técnicas para a região.

$\mathrm{Na}$ colheita, no estádio de maturação fisiológica (R9), as variáveis respostas avaliadas foram: altura da planta (cm, média/10 plantas); diâmetro do colmo (cm, média/10 plantas); número de vagens por planta (média/10 plantas); número de grãos por vagem (média/10 plantas); massa de mil grãos (MMG, em g) segundo a metodologia da RAS (Regras para análise de sementes) (BRASIL, 2009). A produtividade de grãos foi estimada a partir da massa total de grãos produzidos em cada parcela, onde a umidade foi corrigida para $13 \%$ e o valor expresso em $\mathrm{kg} \mathrm{ha}^{-1}$.

Após se verificar os pressupostos básicos para a análise de variância, os dados, foram submetidas às análises obedecendo ao delineamento experimental de blocos completos com tratamentos ao acaso. No caso de efeito significativo dos tratamentos qualitativos, a comparação das médias foi realizada pelo teste de ScottKnott, a 5\%, com o auxílio do pacote estatístico Sisvar (FERREIRA, 2011).

\section{RESULTADOS E DISCUSSÃO}

$\mathrm{Na}$ Tabela 1 se encontra o resumo da análise de variância do experimento. É possível verificar a partir dos dados obtidos que houve diferença significativa $(\mathrm{p}<0,05)$ para a fonte de variação de inoculantes sobre as variáveis respostas altura da planta, número de vagens por planta, massa de mil grãos e produtividade de grãos. Por outro lado, verificou-se que para os caracteres diâmetro do colmo e número de grãos por vagem não houve diferença significativa para as condições testadas.

Tabela 1 - Resumo da análise de variância para as variáveis altura da planta (AP), diâmetro do colmo (DC), número de vagens por planta (NVP), número de grãos por vagem (NGV), massa de mil grãos (MMG) e produtividade (PROD) de feijoeiro comum em função da inoculação e co-inoculação de sementes com estirpes de Rhizobium tropicie Azospirillum brasilense, Campina da Lagoa - PR, 2016.

Table 1 - Summary of variance analysis to the variables plant height (PH), stem diameter (SD), number of pods per plant (NPP), number of grains per pod (NGP), mass of thousand grains (MTS) and yield (Y) due to the inoculation and coinoculation of common-bean seeds with Rhizobium tropici + Azospirillum brasilense, Campina da Lagoa, Parana State, 2016.

\begin{tabular}{|c|c|c|c|c|c|c|}
\hline \multirow{2}{*}{ Fonte Variação } & \multicolumn{4}{|c|}{ F calculado } & & \\
\hline & AP & DC & NVP & NGV & MMG & PROD \\
\hline Bloco & 0,20 ns & $0,66^{\mathrm{ns}}$ & $4,08^{*}$ & $4,80^{*}$ & $0,96^{\mathrm{ns}}$ & 0,19 ns \\
\hline Inoculantes & $8,26 *$ & $0,17 \mathrm{~ns}$ & $7,96 *$ & $2,00^{\mathrm{ns}}$ & $116,01 *$ & $16,46 *$ \\
\hline CV\% & 2,56 & 6,56 & 5,22 & 5,59 & 4,00 & 5,40 \\
\hline Média geral & 100,15 & 0,83 & 13,65 & 7,30 & 234,18 & 2216,75 \\
\hline
\end{tabular}

ns - aceita-se a hipótese H0. ${ }^{*}$ - rejeita-se a hipótese H0.

De acordo com os dados apresentados na Tabela 2, houve diferença significativa para altura das plantas, de modo que os tratamentos com inoculação utilizando $A$. brasilense e $R$. tropici e co-inoculação com $R$. tropici $+A$. brasilense superaram e diferiram significativamente da testemunha, apresentando valores médios de 100,60; 101,80 e 100,80 cm respectivamente, porém não diferindo entre si. A menor altura de plantas foi verificada na testemunha e, provavelmente devido à ausência de nitrogênio no tratamento, pois o mesmo possui correlação positiva com as taxas fotossintéticas da planta (FRANÇA et al., 2008), ou seja, quanto maior a taxa fotossintética da planta maior será seu crescimento.

Esses resultados estão de acordo com Rodrigues et al. (2012) que verificaram a influência da inoculação com Bradyrbizobium sp. e também a combinação de Bradyrbizobium sp.+ Paenibacillus durus em feijão-caupi, sobre a altura de plantas em todas as épocas avaliadas quando comparada a testemunha (sem inoculação). Entretanto, Frigo (2013) em seus estudos com feijão-caupi, não encontrou diferença entre plantas sem inoculação e plantas inoculadas com diferentes estirpes de bactérias fixadoras de nitrogênio. 
Quanto ao número de vagens por planta, de acordo com a Tabela 2, houve diferença significativa entre os tratamentos. Os tratamentos com inoculação utilizando R. tropici e co-inoculação com R. tropici $+A$. brasilense foram superiores à testemunha e não diferiram do tratamento utilizando inoculação com $A$. brasilense. No entanto, para o número de grãos por vagem Tabela 3 , não se observou diferença significativa entre os tratamentos.

$\mathrm{O}$ efeito da inoculação com $A$. brasilense, é atribuído as alterações fisiológicas causada nas plantas devido a liberação de hormônios como auxinas e citocininas que aumentam o crescimento radicular e com isso a planta tende a absorver mais água e nutrientes (ZAFAR et. al., 2012), por isso esses microrganismos são denominados bactérias promotoras de crescimento de plantas.

Tabela 2 - Altura da planta (cm) (AP), diâmetro do colmo (cm) (DC) e número de vagens por planta (média/10 plantas) (NPV) de feijoeiro comum em função da inoculação e co-inoculação de sementes com estirpes de Rhizobium tropici e Azospirillum brasilense, Campina da Lagoa - PR, 2016.

Table 2 - Plant height $(\mathrm{cm})$, stem diameter $(\mathrm{cm})$ and number of pods per plant (average of 10 plants) of common-bean due to the inoculation and co-inoculation of seeds with Rhizobium tropici + Azospirillum brasilense, Campina da Lagoa, Parana State, 2016.

\begin{tabular}{lccc}
\hline Tratamentos & AP & DC & NVP \\
\hline Testemunha & $95,40 \mathrm{~b}^{*}$ & $0,82 \mathrm{a}$ & $12,40 \mathrm{~b}$ \\
Arospirillum & $100,60 \mathrm{a}$ & $0,84 \mathrm{a}$ & $13,60 \mathrm{a}$ \\
brasilense & & & \\
$\begin{array}{l}\text { Rhizobium } \\
\text { tropici }\end{array}$ & $101,80 \mathrm{a}$ & $0,84 \mathrm{a}$ & $14,20 \mathrm{a}$ \\
$\begin{array}{l}\text { A. brasilense }+ \\
\text { R. tropici }\end{array}$ & $102,80 \mathrm{a}$ & $0,84 \mathrm{a}$ & $14,40 \mathrm{a}$ \\
\hline DMS & & & \\
CV\% & 4,12 & 0,10 & 1,71 \\
\hline
\end{tabular}

$* \overline{\text { Médias seguidas pela mesma letra não diferem entre si pelo teste de }}$ Scott-Knott, a $\mathrm{p} \leq 0,05$ de probabilidade de erro.

Desse modo, a simbiose melhora o desenvolvimento das plantas, resultando em aumento nos componentes de rendimento conforme verificado por Yadegari (2014). Este autor verificou que o feijoeiro comum obteve incrementos nos componentes de rendimento número de vagens por planta e número de grãos por vagem quando as sementes foram inoculadas com R. tropici e também em associação com outras estirpes.

Souza et al. (2011) observaram o efeito do $R$. tropici sobre essa variável apenas quando não houve associação com adubação nitrogenada, onde as plantas inoculadas apresentaram 30\% a mais no número de vagens que as plantas não inoculadas, Peres et al. (2014) encontraram maior número de vagens com a coinoculação quando se comparou à testemunha ou com a aplicação de $80 \mathrm{~kg}$ de $\mathrm{N} \mathrm{ha}^{-1} \mathrm{em}$ cobertura. Por outro lado, quando as bactérias foram inoculadas isoladamente não verificaram diferenças estatísticas entre os tratamentos. No segundo ano de avaliação o R. tropici e a co-inoculação foram estatisticamente inferiores aos demais tratamentos.

Para a massa de mil grãos, a associação das estirpes $\mathrm{R}$. tropici $+A$. brasilense proporcionou os melhores resultados (253,36 g) (Tabela 3), evidenciando que o efeito combinado das bactérias é extremamente benéfico para o feijoeiro comum, visto que ao se aplicar A. brasilense isoladamente, a massa de mil grãos foi $10 \%$ inferior a co-inoculação e a do tratamento com R. tropici 8\%. Yadegari (2014) encontrou resultados semelhantes utilizando R. tropici isolado ou em associação com bactérias promotoras de crescimento de plantas.

Tabela 3 - Número de grãos por vagem (média/10 plantas) (NGV), massa de mil grãos (em, g) (MMG) e produtividade de grãos $\left(\mathrm{kg} \mathrm{ha}^{-1}\right)$ (PROD) de feijoeiro comum em função da inoculação e co-inoculação de sementes com estirpes de Rhizobium tropici e Azospirillum brasilense, Campina da Lagoa - PR, 2016. Table 3 - Number of grains per pod (NGP), mass of hundred grains (MHG) and yield (Y) of common-bean due to the inoculation and co-inoculation of seeds with Rhizobium tropici + Azospirillum brasilense, Campina da Lagoa, Parana State, 2016.

\begin{tabular}{lccc}
\hline Tratamentos & NGV & MMG & PROD \\
\hline Testemunha & $7,00 \mathrm{a}^{*}$ & $220,49 \mathrm{~d}$ & $1944,53 \mathrm{c}$ \\
Azospirillum & $7,20 \mathrm{a}$ & $228,12 \mathrm{c}$ & $2156,79 \mathrm{~b}$ \\
brasilense & & & \\
Rbizobium tropici & $7,20 \mathrm{a}$ & $234,76 \mathrm{~b}$ & $2317,26 \mathrm{a}$ \\
A. brasilense + R. & $7,40 \mathrm{a}$ & $253,36 \mathrm{a}$ & $2448,45 \mathrm{a}$ \\
tropici & & & \\
\hline DMS & 1,03 & 5,25 & 193,41 \\
CV\% & 7,81 & 2 & 4,82 \\
\hline
\end{tabular}

$*$ Médias seguidas pela mesma letra não diferem entre si pelo teste de Scott-Knott, a $\mathrm{p} \leq 0,05$ de probabilidade de erro.

Observou-se diferença significativa para a variação inoculação sobre a produtividade de grãos (Tabela 3). O tratamento com co-inoculação apresentou valor de $2448,45 \mathrm{~kg} \mathrm{ha}^{-1}$, diferindo significativamente dos tratamentos com inoculação utilizando a estirpe $A$. brasilense (2156,79 kg ha-1) e testemunha $(1944,53 \mathrm{~kg} \mathrm{ha}$ 1), no entanto, não diferindo do tratamento inoculado com R. tropici. A inoculação com R. tropici e A. brasilense superaram e diferiram significativamente da testemunha, apresentando produtividades 7 e $10 \%$ superiores, respectivamente. 
A superioridade da co-inoculação sobre os demais tratamentos são devido aos efeitos combinados que as duas bactérias proporcionam, aumentando o número de nódulos, a massa dos nódulos, o comprimento e a massa das raízes (HUNGRIA et al., 2013; AUNG et al., 2013), propiciando maior aporte de nitrogênio para a planta e aumentando sua capacidade em absorver água e nutrientes devido ao maior volume de solo explorado.

Hungria et al. (2013) obtiveram aumento de $8,3 \%$ na produtividade quando inocularam as sementes de feijoeiro comum com $R$. tropici e 19,6\% e quando além da inoculação aplicaram $A$. brasilense no sulco. Os resultados são uma média de 5 trabalhos realizados à campo em Londrina e Ponta Grossa por três estações de cultivo (2009, 2010 e 2011).

Gitti et al. (2012) trabalhando com A. brasilense obtiveram um acréscimo de $101 \mathrm{~kg} \mathrm{ha}^{-1}$ de grãos quando se comparou à produção do tratamento sem inoculação em plantas de feijoeiro comum. Por outro lado, Souza et al. (2011) trabalhando com a cultivar IAC Alvorada não verificaram influência da inoculação de estirpes $R$. tropici sobre a produtividade de grãos do feijoeiro em relação à testemunha sem inoculação em dois anos de testes. Peres et al. (2014) também não encontraram efeito da inoculação e co-inoculação sobre a produtividade quando compararam a testemunha sem inoculação) ou com a aplicação de $80 \mathrm{~kg} \mathrm{~N} \mathrm{ha}^{-1}$ em duas safras de avaliação.

\section{CONCLUSÕES}

A inoculação com Rhizobium tropici e Arospirillum brasilense e a associação de ambos proporcionaram maior altura de plantas e número de vagens por planta. A co-inoculação com Rhizobium tropici + Azospirillum brasilense apresentou a maior massa de mil grãos e as maiores produtividades de grãos foram obtidas com o Rhizobium tropici e com a associação de Rhizobium tropici + Azospirillum brasilense.

\section{REFERÊNCIAS}

AUNG, T.T.; TITTABUTR, P.; BOONKER, N.; HERRIDGE, D.; TEAUMROONG, N. Coinoculation effects of Bradyrbizobium japonicum and Azospirillum sp. on competitive nodulation and rhizosphere eubacterial community structures of soybean under rhizobia-established soil conditions. African Journal of Biotechnology, v. 12, n. 20, p. 2850-2862, 2013.
BENINTENDE, S.; UHRICH, W.; HERRERA, M.; GANGGE, F.; STERREN, M.; BENINTENDE, M. Comparación entre Coinoculación con Bradyrbizobium japonicum y Azospirillum brasilense e Inoculación simple con Bradyrbizobium japonicum en la Nodulación, Crecimiento y Acumulación de $\mathrm{N}$ en el Cultivo de Soja. Agriscientia, v. 27, n. 2, p. 71-77, 2010.

CHAPARRO, J.M.; SHEFLIN, A.M.; MANTER, D.K.; VIVANCO, J.M. Manipulating the soil microbiome to increase soil health and plant fertility. Biology and Fertility of Soils, v. 48, n. 5, p. 489-499, 2012.

CHIBEBA, A.M.; GUIMARÃES, M.F.; BRITO, O.R.; NOGUEIRA, M.A.; ARAUJO, R.S.; HUNGRIA, M. Co-inoculation of soybean with Bradyrbizobium and Azospirillum promotes early nodulation. American Journal of Plant Science, v. 6, n. 10, p.1641-1649, 2015.

CONAB - Companhia Nacional de Abastecimento. Acompanhamento da safra brasileira de grãos. Brasília: Conab, v. 3, n. 1, 136 p. 2015.

COSTA, E.M.; CARVALHO F.; ESTEVES, J.A.; NÓBREGA, R.S.A.; MOREIRA, F.M.S. Resposta da soja a inoculação e co-inoculação com bactérias promotoras do crescimento vegetal e Bradyrhizobium. Enciclopédia Biosfera, 10:1678-1689, 2014.

DE BRUIJN, F. Biological nitrogen fixation, 2 ed. New Jersey: John Wiley \& Sons, 2015, 1260 p.

EMBRAPA - Empresa Brasileira de Pesquisa Agropecuária. Sistema Brasileiro de Classificação de Solo. $3^{\mathrm{a}}$ ed. Rio de Janeiro: Centro Nacional de Pesquisa de Solos, 2013. 342 p.

FANCELLI, A. L.; DOURADO NETO, D. Produção de feijão. 2. ed. Piracicaba: Livroceres, 2007. 386 p.

FERREIRA, D.F. Sisvar: A computer statistical analysis system. Ciência e Agrotecnologia, Lavras, v. 35, n. 6, p. 10391042, 2011.

FRANÇA, M.G.C.; ARAÚJO, A.P.; PEREYRA, R.O.; RAMOS, F.T. Relações entre crescimento vegetativo e acúmulo de nitrogênio em duas cultivares de arroz com arquiteturas contrastantes. Acta Botânica Brasílica, v. 22, n. 1, p. 43-49. 2008.

FRIGO, G.R. Feijão-caupi submetido à inoculação com rizóbio $e$ cultivado em Latossolo do cerrado Mato-Grossense. Dissertação (Mestrado em Engenharia agrícola). 69f. 
Universidade Federal de Mato Grosso - UFMT, Rondonópolis, 2013.

GITTI, D. de C.; ARF, O.; KANEKO, F.H.; RODRIGUES, R.A.F.; BUZETTI, S.; PORTUGAL, J.R.; CORSINI, D.C.D.C. Inoculação de Azospirillum brasilense em cultivares de feijões cultivados no inverno. Revista Agrarian, v.5, n.15, p.36-46, 2012.

HUNGRIA. M.; NOGUEIRA, M.A.; ARAUJO R.S. Soybean seed co-inoculation with Bradyrbizobium spp. and Azospirillum brasilense: a new biotechnological tool to improve yield and sustainability. American Journal of Plant Science, v. 6, n. 10, p. 811-817, 2015.

HUNGRIA, M.; NOGUEIRA, M.A.; ARAUJO, R.S. Co-inoculation of soybeans and common beans with rhizobia and azospirilla: strategies to improve sustainability. Biology and Fertility of Soils, v. 49, n. 7, p. 791-801, 2013.

PELEGRIN, R.; MERCADANTE, F.M.; OBTUSO, I.M.N.; OBTUSO, A.A. Resposta da cultura do feijoeiro à adubação nitrogenada e a inoculação com rizóbio. Revista Brasileira de Ciência do Solo, v. 33, n. 1, p. 219-226. 2009

PERES, M. R.; RODRIGUES, R. A. F.; ARF, O.; PORTUGAL, J. R.; CORSINI, D. D. C. Co-inoculation of Rhizobium tropici and Azospirillum brasilense in common beans grown under two irrigation depths. Revista Ceres, v. 63 , n. 2 , p. 198-207, 2016.

RODRIGUES, A.C.; ANTUNES, J.E.L.; MEDEIROS, V.V. de; BARROS, B.G. de F.; FIGUEIREDO, M. do V.B. Resposta da co-inoculação de bactérias promotoras de crescimento em plantas e Bradyrbizobium sp. em caupi. Bioscience Journal, v. 28, n. 1, p. 196-202, 2012.

RUFINI, M.; FERREIRA, P.A.A.; SOARES, B.L.; OLIVEIRA, D.P.; ANDRADE, M.J.B.; MOREIRA, F.M.S. Simbiose de bactérias fixadoras de nitrogênio com feijoeiro-comum em diferentes valores de $\mathrm{pH}$. Pesquisa Agropecuária Brasileira. v. 46, n. 1, p. 81-8, 2011.

SOUZA, E.F.C.; SORATTO, R.P.; PAGANI, F.A. Aplicação de nitrogênio e inoculação com rizóbio em feijoeiro cultivado após milho consorciado com braquiária. Pesquisa Agropecuária Brasileira, v. 46, n. 4, p. 370-377, 2011.

YADEGARI, M. Inoculation of bean (Phaseolus vulgaris) seeds with Rizobium phaseoli and plant growth promoting rhizobacteria. Advances in Environmental Biology, v. 8, n. 2, p. 419-424, 2014.

ZAFAR, M.; ABBASI, M. K.; KHAN, M. A.; KHALIQ, A.; SULTAN, T.; ASLAM, M. Effect of Plant Growth Promoting Rhizobacteria on Growth, Nodulation and Nutrient Accumulation of Lentil Under Controlled Conditions. Pedosphere, v. 22, n. 6, p. 848-859, 2012. 